TITLE:

\title{
Effects of alloying elements on thermal desorption of helium in $\mathrm{Ni}$ alloys
}

$\operatorname{AUTHOR}(\mathrm{S}):$

Xu, Q.; Cao, X.Z.; Sato, K.; Yoshiie, T.

\section{CITATION:}

Xu, Q.... [et al]. Effects of alloying elements on thermal desorption of helium in Ni alloys. Journal of Nuclear Materials 2012, 431(1-3): 57-59

ISSUE DATE:

2012-12

URL:

http://hdl.handle.net/2433/175277

\section{RIGHT:}

@ 2011 Elsevier B.V.; この論文は出版社版でありません。引用の際には 出版社版をご確認ご利用ください。; This is not the published version. Please cite only the published version. 


\title{
Effects of alloying elements on thermal desorption of helium in $\mathrm{Ni}$ alloys
}

\author{
Q. Xu, X. Z. Cao, K. Sato and T. Yoshiie \\ Research Reactor Institute, Kyoto University, Osaka 590-0494, Japan
}

\begin{abstract}
It is well known that the minor elements $\mathrm{Si}$ and $\mathrm{Sn}$ can suppress the formation of voids in $\mathrm{Ni}$ alloys. In the present study, to investigate the effects of $\mathrm{Si}$ and $\mathrm{Sn}$ on the retention of helium in Ni alloys, $\mathrm{Ni}, \mathrm{Ni}-\mathrm{Si}$, and $\mathrm{Ni}-\mathrm{Sn}$ alloys were irradiated by $5 \mathrm{keV} \mathrm{He}$ ions at $723 \mathrm{~K}$. Thermal desorption spectroscopy (TDS) was performed at up to $1520 \mathrm{~K}$, and microstructural observations were carried out to identify the helium trapping sites during the TDS analysis. Two peaks, at 1350 and $1457 \mathrm{~K}$, appeared in the TDS spectrum of Ni. On the basis of the microstructural observations, the former peak was attributed to the release of trapped helium from small cavities and the latter to its release from large cavities. Small-cavity helium trapping sites were also found in the Ni-Si and Ni-Sn alloys, but no large cavities were observed in these alloys. In addition, it was found that the oversized element Sn could trap He atoms in the Ni-Sn alloy.
\end{abstract}

PACS number(s): 61.30.Jf, 61.43.Er, 61.72.jd, 61.72.jj, 61.82.Rx 


\section{Introduction}

With the development of spallation target technology, interest in the behavior of helium in solids has increased. Helium is generated in materials by the nuclear reaction of $(\mathrm{n}, \alpha)$, which increases with increasing neutron energy. Helium, which has a strong interaction with vacancies $[1,2]$, can form a high density of helium bubbles. Helium, and especially He bubbles, can degrade the ductility and thermal conductivity of a spallation target. Therefore, it is important to find materials with low helium retention and/or better resistance to He bubble formation.

The microstructural evolution in $\mathrm{Ni}$ and its binary alloys has been investigated, and it is well known that the minor elements $\mathrm{Si}$ and $\mathrm{Sn}$ can suppress the formation of voids in $\mathrm{Ni}$ alloys [3-8]. The volume size factors, which are the ratio of the difference in volume between the solute and solvent atoms to the volume size of the solvent atom, of Si and $\mathrm{Sn}$ in $\mathrm{Ni}$ are $-5.81 \%$ and $74.08 \%$ [9], respectively. As $\mathrm{Si}$ is an undersized element in $\mathrm{Ni}$, interstitials will be easily trapped by the $\mathrm{Si}$. With increasing dose, a large number of trapped interstitials and their clusters will be formed. These function as effective sites for the annihilation of freely migrating vacancies, and suppress the growth of microvoids [5]. The oversized element $\mathrm{Sn}$, on the other hand, may trap interstitials and vacancies. As a result, the formation of interstitial-type dislocation loops and voids is suppressed due to the recombination of interstitials and vacancies at Sn defect sinks [10].

In the present study, the effects of alloying elements $\mathrm{Si}$ and $\mathrm{Sn}$ on the accumulation of helium in Ni alloys were investigated.

\section{Experimental procedure}


Pure nickel (99.99\%) and its binary alloys containing 2 at\% Si and Sn were examined. Well-annealed specimens were irradiated with $5 \mathrm{keV} \mathrm{He}^{+}$ions using an Omegatron gun, in which mono-energetic $\mathrm{He}^{+}$ions were collimated and mass-analyzed [11], at a flux of $5.0 \times 10^{17} \mathrm{He}^{+} / \mathrm{m}^{2}$ s to the same nominal dose of $5.0 \times 10^{19} \mathrm{He}^{+} / \mathrm{m}^{2}$ at $723 \mathrm{~K}$. In addition, to investigate the helium trapping sites in Ni-Sn alloy in detail, He implantation was carried out in both well-annealed samples and samples containing only dislocations. The annealed samples were cold rolled to $10 \%$ of their original thickness at room temperature and then annealed at $773 \mathrm{~K}$ for $1 \mathrm{~h}$ in high vacuum to annihilate vacancies and vacancy clusters. He implantation was then performed at a low energy of $150 \mathrm{eV}$ in order to avoid displacement damage. Afterwards, thermal desorption spectroscopy (TDS) was performed by heating the samples at $1 \mathrm{~K} / \mathrm{s}$ to $1523 \mathrm{~K}$ using infrared irradiation. During heating, the helium release was monitored by a quadrupole mass analyzer. The pressure within the TDS chamber was reduced to below $1.0 \times 10^{-5} \mathrm{~Pa}$ by vacuum pump before heating the samples. The microstructures of the irradiated samples were investigated using transmission electron microscopy (TEM).

\section{Results and discussion}

No helium desorption peak appeared from un-irradiated $\mathrm{Ni}$, Ni-Si, or Ni-Sn alloys during heating of the samples to $1523 \mathrm{~K}$. Fig. 1 shows helium thermal desorption from Ni (a), Ni-Si (b), and Ni-Sn, (c) after $5 \mathrm{keV} \mathrm{He}{ }^{+}$irradiation to a nominal dose of $5.0 \times 10^{19}$ $\mathrm{He}^{+} / \mathrm{m}^{2}$ at $723 \mathrm{~K}$. The amount of retained helium in the $\mathrm{Ni}$ and binary $\mathrm{Ni}$ alloys were calculated based on the TDS data to be $2.0 \times 10^{19}$ in Ni, $4.0 \times 10^{19}$ in Ni-Si, and $3.2 \times 10^{19}$ $\mathrm{He} / \mathrm{m}^{2}$ in Ni-Sn, respectively. Two peaks appeared from pure Ni, at about 1350 and $1457 \mathrm{~K}$. Although two peaks also appeared in the Ni-Sn alloy, the first peak shifted to a lower 
temperature by $175 \mathrm{~K}$. In the Ni-Si alloy, on the other hand, only one peak appeared. The different helium desorption peaks corresponded to different helium trapping sites. In order to identify these helium trapping sites, TEM observations were carried out. No defects were observed in un-irradiated samples. The microstructures of $\mathrm{Ni}, \mathrm{Ni}-\mathrm{Si}$, and Ni-Sn after irradiation are shown in Figs. 2, 3, and 4, respectively. In addition, typical microstructures during the annealing of irradiated samples to high temperatures in those alloys are also shown. After irradiation at $723 \mathrm{~K}$, black dots, which are thought to be interstitial-type dislocation loops, were observed in all alloys. Dislocations and cavities with an average diameter of $5 \mathrm{~nm}$ and a maximum diameter of $30 \mathrm{~nm}$ were observed after annealing irradiated samples at $1223 \mathrm{~K}$, which was just below the temperature of the first peak, as shown in Fig. 1(a), for $5 \mathrm{~min}$ in $\mathrm{Ni}$. These cavities grew larger by the Oswald ripening process, to an average diameter of $70 \mathrm{~nm}$ after subsequent annealing for $5 \mathrm{~min}$ at $1373 \mathrm{~K}$, which was just below the temperature of the second peak, as shown in Fig. 1 (a). According to TEM observations, small and large cavities were formed before $1350 \mathrm{~K}$ and $1457 \mathrm{~K}$, respectively, as shown in Fig. 2, and the first and the second peaks of the helium thermal desorption were related to these small and large cavities, respectively. In the Ni-Si alloy, small cavities with an average diameter of $20 \mathrm{~nm}$ were observed after annealing an irradiated sample at $1243 \mathrm{~K}$ for $5 \mathrm{~min}$, as shown in Fig. 3. This suggests that the helium trapping sites for the peak shown in Fig. 1(b) were small cavities. In the Ni-Sn alloy, dislocations and dislocation loops were observed after annealing an irradiated sample at $1103 \mathrm{~K}$ for $5 \mathrm{~min}$, and small cavities with an average diameter of $10 \mathrm{~nm}$ were observed after subsequent annealing at $1323 \mathrm{~K}$ for $5 \mathrm{~min}$, as shown in Fig. 4. Comparing the microstructural evolution before and after helium thermal desorption, the helium trapping sites for the first and the second peaks of the Ni-Sn alloy appeared to be related to 
dislocations and small cavities, respectively. It has been reported that dislocations can also act as helium trapping sites in $\mathrm{Ni}$ irradiated by $5 \mathrm{keV} \mathrm{He}^{+}$at room temperature, and helium is released at $940 \mathrm{~K}$ during thermal annealing [11]. In order to identify whether the first peak of helium thermal desorption at $1175 \mathrm{~K}$ can be attributed to the release of trapped helium from dislocations, TDS measurements were carried out in well-annealed Ni-Sn samples and Ni-Sn samples containing only dislocations. These TDS results each contained a single peak, which was located at $1146 \mathrm{~K}$ in He-implanted Ni-Sn alloy and at $1020 \mathrm{~K}$ in Ni-Sn alloy containing dislocations, respectively. Therefore, the helium trapping sites for the first peak of Ni-Sn alloy irradiated with $5 \mathrm{keV} \mathrm{He}^{+}$ions were not dislocations, but were the oversized element $\mathrm{Sn}$. Sato et al. reported that $\mathrm{Sn}$ atoms act not only as sinks for vacancies, but also as sinks for interstitials [10], and the present results indicate that Sn atoms also act as sinks for interstitial helium.

It is well known that void formation is suppressed in Ni-Si and Ni-Sn alloys, compared with that in $\mathrm{Ni}$ [5-8]. In the present study, the nucleation of cavities was delayed in $\mathrm{Ni}-\mathrm{Si}$ and Ni-Sn alloys relative to that in $\mathrm{Ni}$. In addition, cavities grew during the annealing of irradiated Ni samples at high temperatures; however, the growth of cavities in Ni-Si and Ni-Sn was suppressed. Therefore, helium-vacancy clusters were dispersed in the Ni-Si and Ni-Sn alloys. The migration of helium-vacancy clusters is more difficult than that of free helium or vacancies, so the nucleation of cavities was delayed. Si and Sn alloying elements probably act as trapping sites for helium-vacancy clusters, but it is necessary to investigate the specific interactions of Si and $\mathrm{Sn}$ alloying elements with helium and vacancies in more detail. 
Although Ni is not a good material for spallation targets, the present results give some information to assist in the selection of a spallation target. For example, the selection of appropriate alloying elements can inhibit the migration of vacancies.

\section{Conclusions}

In order to investigate the effects of alloying elements on helium retention in $\mathrm{Ni}$ and its binary alloys, $\mathrm{Ni}, \mathrm{Ni}-\mathrm{Si}$, and $\mathrm{Ni}-\mathrm{Sn}$ were irradiated by $5 \mathrm{keV} \mathrm{He}^{+}$ions at $723 \mathrm{~K}$. The helium trapping sites were cavities in $\mathrm{Ni}$ and the Ni-Si alloy, and the oversized element $\mathrm{Sn}$ and cavities in the Ni-Sn alloy. Compared with the nucleation and growth of cavities in pure $\mathrm{Ni}$, the addition of an $\mathrm{Si}$ or $\mathrm{Sn}$ alloying element suppressed the nucleation and growth of cavities. 


\section{References}

[1] M.L. Swanson, J.R. Parsons, C.W. Hoelke, Rad. Eff. 9 (1971) 249.

[2] N.Q. Lam, P.R. Okamoto, Mater. Res. Soc. Bull. May (1994) 703.

[3] K. Yamakawa, Y. Shimomura, J. Nucl. Mater. 264 (1999) 319.

[4] K. Niwase, T. Ezawa, T. Tanabe, J. Nucl. Mater. 212 (1994) 364.

[5] T. Yoshiie, Q. Xu, Y. Satoh, H. Ohkubo, M. Kiritani, J. Nucl. Mater. 283-287 (2000) 229.

[6] T. Yoshiie, T. Ishizaki, Q. Xu, Y. Satoh, M. Kiritani, J. Nucl. Mater. 307-311 (2002) 924.

[7] Q. Xu, T. Yoshiie, J. Nucl. Mater. 307-311 (2002) 380.

[8] Q. Xu, T. Yoshiie, H. Watanabe, N. Yoshida, J. Nucl. Mater. 367-370 (2007) 361.

[9] H.W. King, J. Mater. Sci. 1 (1966) 79.

[10] K. Sato, T. Yoshiie, Q. Xu, J. Japan Inst. Metals 74 (2010) 572.

[11] X.Z. Cao, Q. Xu, K. Sato, T. Yoshiie, J. Nucl. Mater. 412 (2011) 165. 


\section{Figure Captions}

Fig. 1 He thermal desorption in $\mathrm{Ni}(\mathrm{a}), \mathrm{Ni}-\mathrm{Si}(\mathrm{b})$, and Ni-Sn (c) irradiated by $5 \mathrm{keV} \mathrm{He}^{+}$ ions to $5.0 \times 10^{19} \mathrm{He}^{+} / \mathrm{m}^{2}$ at $723 \mathrm{~K}$.

Fig. 2 Microstructures in Ni after irradiation and annealing. (a) after irradiation by $5 \mathrm{keV}$ $\mathrm{He}^{+}$ions to $5.0 \times 10^{19} \mathrm{He}^{+} / \mathrm{m}^{2}$ at $723 \mathrm{~K}$; (b) irradiated sample annealed at $1223 \mathrm{~K}$ for $5 \mathrm{~min}$; (c) irradiated sample after subsequent annealing at $1373 \mathrm{~K}$ for $5 \mathrm{~min}$.

Fig. 3 Microstructures in Ni-Si after irradiation and annealing. (a) after irradiation by 5 $\mathrm{keV} \mathrm{He}{ }^{+}$ions to $5.0 \times 10^{19} \mathrm{He}^{+} / \mathrm{m}^{2}$ at $723 \mathrm{~K}$; (b) irradiated sample annealed at 1243 $\mathrm{K}$ for $5 \mathrm{~min}$.

Fig. 4 Microstructures in Ni-Sn after irradiation and annealing. (a) after irradiation by 5 $\mathrm{keV} \mathrm{He}{ }^{+}$ions to $5.0 \times 10^{19} \mathrm{He}^{+} / \mathrm{m}^{2}$ at $723 \mathrm{~K}$; (b) irradiated sample annealed at 1103 $\mathrm{K}$ for $5 \mathrm{~min}$; (c) irradiated sample after subsequent annealing at $1323 \mathrm{~K}$ for $5 \mathrm{~min}$. 

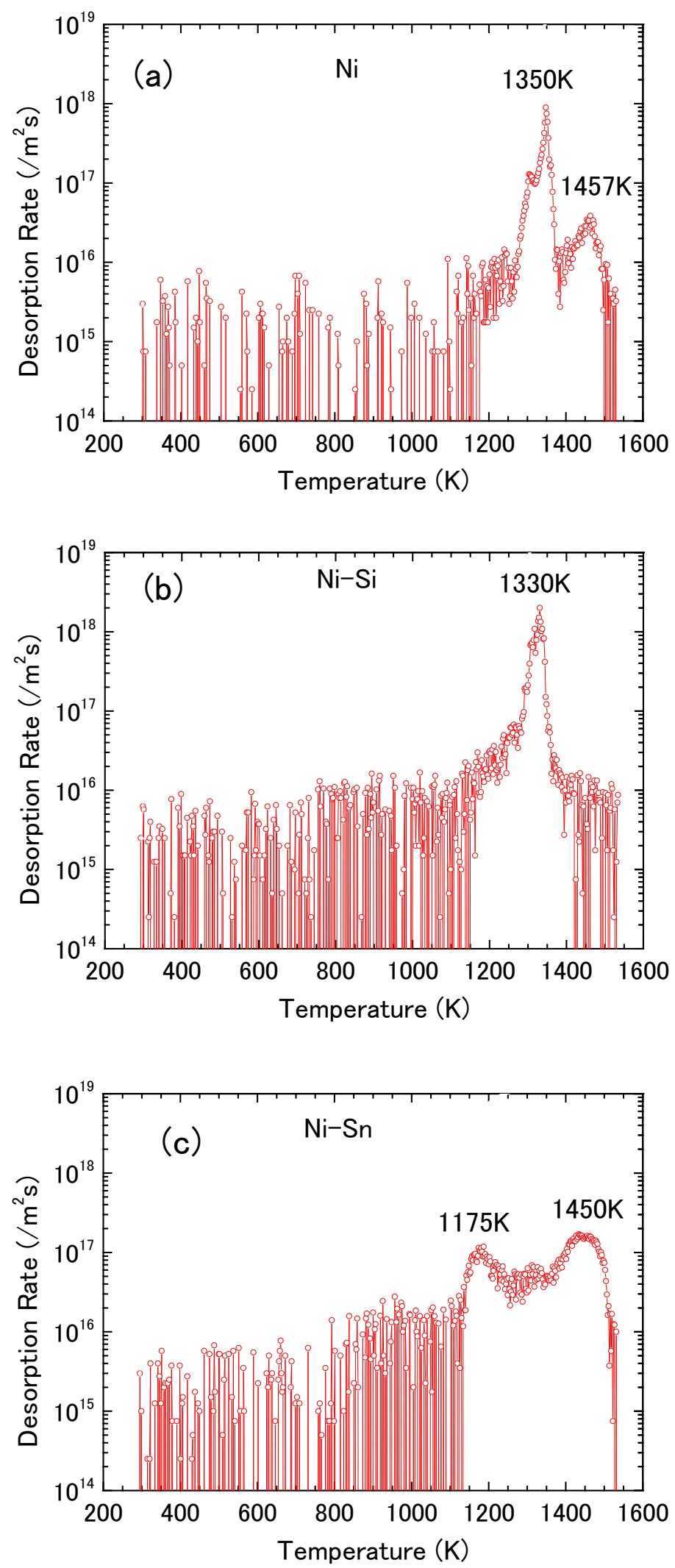

Fig. $1 \mathrm{He}$ thermal desorption in $\mathrm{Ni}(\mathrm{a}), \mathrm{Ni}-\mathrm{Si}(\mathrm{b})$ and $\mathrm{Ni}-\mathrm{Sn}$

(c) irradiated by $5 \mathrm{keV} \mathrm{He}+$ ions to $5.0 \times 10^{19} \mathrm{He}+/ \mathrm{m}^{2}$ at $723 \mathrm{~K}$. 


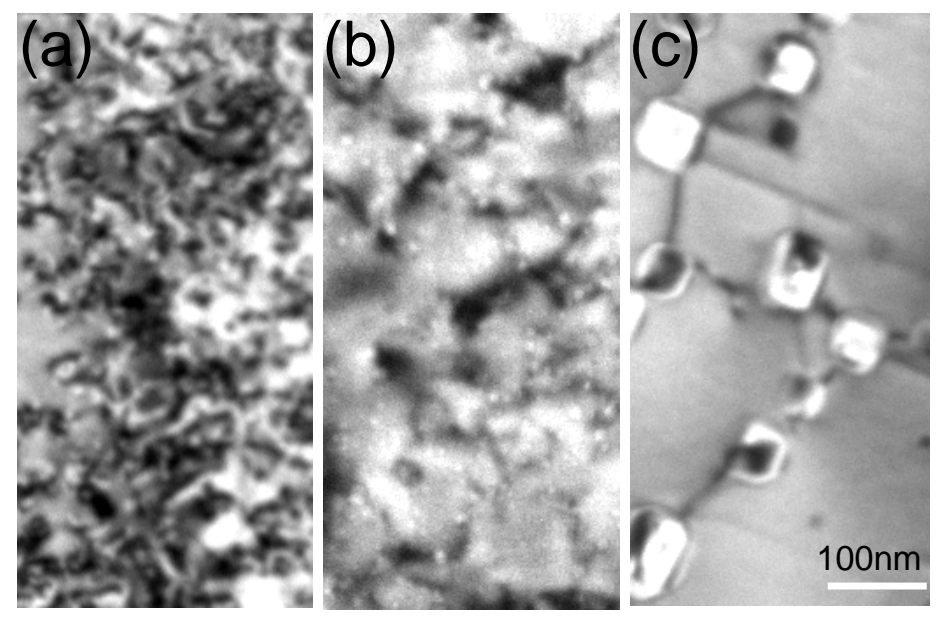

Fig. 2 Microstructures in Ni after irradiation and anneal.

(a) after irradiated by $5 \mathrm{keV} \mathrm{He}+$ ions to $5.0 \times 10^{19} \mathrm{He}+/ \mathrm{m}^{2}$ at $723 \mathrm{~K}$;

(b) irradiated sample annealed at $1223 \mathrm{~K}$ for $5 \mathrm{~min}$;

(c) irradiated sample after subsequent annealing at $1373 \mathrm{~K}$ for $5 \mathrm{~min}$. 


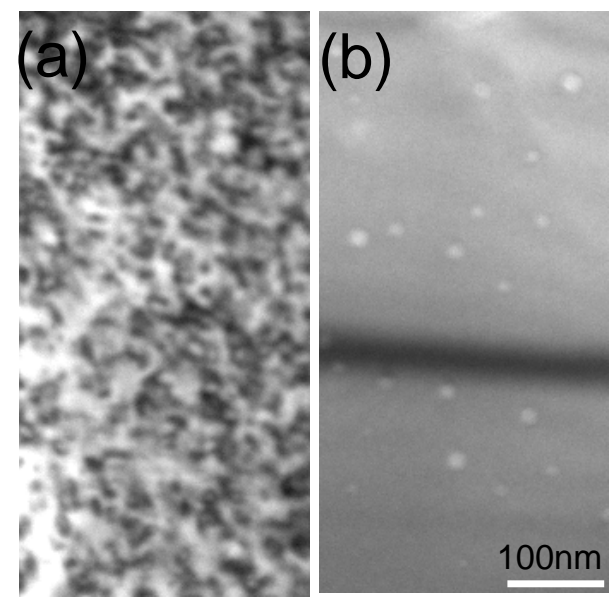

Fig. 3 Microstructures in Ni-Si after irradiation and anneal.

(a) after irradiated by $5 \mathrm{keV} \mathrm{He}+$ ions to $5.0 \times 10^{19} \mathrm{He}+/ \mathrm{m}^{2}$ at $723 \mathrm{~K}$;

(b) irradiated sample annealed at $1243 \mathrm{~K}$ for $5 \mathrm{~min}$. 

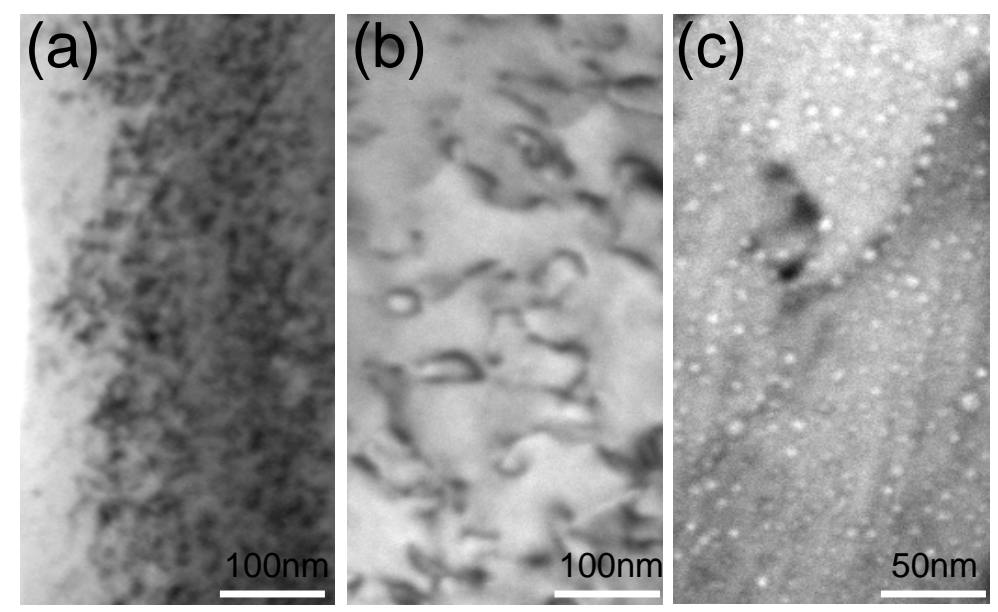

Fig. 4 Microstructures in Ni-Sn after irradiation and anneal.

(a) after irradiated by $5 \mathrm{keV} \mathrm{He}+$ ions to $5.0 \times 10^{19} \mathrm{He}+/ \mathrm{m}^{2}$ at $723 \mathrm{~K}$;

(b) irradiated sample annealed at $1103 \mathrm{~K}$ for $5 \mathrm{~min}$;

(c) irradiated sample after subsequent annealing at $1323 \mathrm{~K}$ for $5 \mathrm{~min}$. 